CLINICAL STUDY

\title{
A thyroxine absorption test followed by weekly thyroxine administration: a method to assess non-adherence to treatment
}

\author{
J N Walker, P Shillo $^{1}$, V Ibbotson ${ }^{1}$, A Vincent, N Karavitaki, A P Weetman ${ }^{1}$, J A H Wass and A Allahabadia ${ }^{1}$ \\ Department of Endocrinology, Oxford University Hospitals NHS Trust, OCDEM, Oxford OX3 7LJ, UK and ${ }^{1}$ Department of Endocrinology, Royal \\ Hallamshire Hospital, Sheffield Teaching Hospitals NHS Foundation Trust, Sheffield, UK
}

(Correspondence should be addressed to J N Walker; Email: neilwalker1@nhs.net)

\begin{abstract}
Objective: For patients who remain hypothyroid despite the administration of what would seem adequate doses of levothyroxine $\left(\mathrm{L}-\mathrm{T}_{4}\right)$, the underlying cause can be difficult to determine. The possibility of a biological cause should first be explored; however, in the majority of cases, poor adherence to medication is likely to be the main cause of treatment failure. When non-adherence is suspected but not volunteered, options to confirm the suspicion are limited. In this study, we identified patients for whom known drugs and pathological causes of $\mathrm{L}_{-} \mathrm{T}_{4}$ malabsorption were excluded, and despite often high doses of $\mathrm{L}^{-\mathrm{T}_{4}}$, the patients remained hypothyroid.

Design: Using a weight-determined oral $\mathrm{L}_{-} \mathrm{T}_{4}$ bolus administration, absorption was initially assessed in 23 patients. In nearly all patients, this was shown to be maximal at $120 \mathrm{~min}$ post-ingestion. This was then followed by the continued administration of a weekly $\mathrm{T}_{4}$ bolus for a 4 -week period after which TSH and free $\mathrm{T}_{4}\left(\mathrm{fT}_{4}\right)$ levels were recorded.

Results: All patients showed a rise in $\mathrm{fT}_{4}$ at 120 min following the administration of the $\mathrm{L}_{-} \mathrm{T}_{4}$ bolus, with a mean increase of $54 \pm 3 \%$ from baseline. Following the treatment period, using an equivalent weekly $\mathrm{L}-\mathrm{T}_{4}$ dose, which was significantly less than that of the daily dose taken by the patients before the test, TSH reduced from baseline in $\sim 75 \%$ of cases.

Conclusion: Using this combination of tests allows significant malabsorptive problems to be identified first and then potential non-adherence to be demonstrated. A management plan can then be implemented to increase adherence, aiming to improve treatment outcomes.
\end{abstract}

European Journal of Endocrinology 168 913-917

\section{Introduction}

Hypothyroidism has been successfully treated using synthetic thyroxine $\left(\mathrm{T}_{4}\right)$ since $1927(1)$. The detrimental effects of hypothyroidism are well documented (2) and an optimal daily dose of $1.6-1.8 \mu \mathrm{g} /$ body weight $(\mathrm{kg})$ per day of levothyroxine $\left(\mathrm{L}-\mathrm{T}_{4}\right)$ is generally agreed as an appropriate replacement dose to restore the TSH into the normal range for the majority of hypothyroid patients (3). The absorption of oral $\mathrm{L}_{-} \mathrm{T}_{4}$ occurs in the small intestine $(60-80 \%$ of the ingested dose), is maximal when the stomach is empty, and maximal absorption takes place within the first $3 \mathrm{~h}$ of ingestion (4).

For patients who require larger doses of $\mathrm{L}_{-} \mathrm{T}_{4}$ than expected, the underlying cause can be difficult to determine. The possibility of a biological cause should first be explored. A number of commonly used drugs, e.g. bile acid sequestering agents, ferrous sulphate, aluminium hydroxide, calcium carbonate and protonpump inhibitors (5), as well as the ingestion of coffee (6) have been documented to interfere with the absorption of $\mathrm{L}_{-} \mathrm{T}_{4}$. Other drugs may increase the excretion or turnover of $\mathrm{T}_{4}$, e.g. phenytoin, rifampicin and carbamazepine. Malabsorptive disorders, e.g. coeliac disease and inflammatory bowel disease, can also increase the requirement for $\mathrm{L}_{-} \mathrm{T}_{4}$ by reducing the fraction of the ingested dose that is absorbed. Other causes include atrophic gastritis, Helicobacter pylori, liver disease and previous gastrointestinal surgery. After excluding all these causes, rarely malabsorption can still be the cause, the reason for which may remain undetermined (7). However, in the majority of cases, a lack of adherence to prescribed medication is likely to be the reason for treatment failure (3).

Low compliance with prescribed medical interventions is an ever present and complex problem, especially for patients with chronic illness. Adherence to medication is the key link between a process and an outcome in medical care and without it, the likelihood of treatment failure is high (8). In addition, poor adherence poses a significant financial burden upon health care systems (9) and is a source of ongoing frustration to doctors (10), often placing a strain on the doctor-patient relationship. A number of factors have been suggested to contribute to non-adherence. These include the patients' beliefs about medications, 
an absence of symptoms, the fear of adverse effects and the confidence in the doctor-patient relationship (11).

A non-judgemental discussion with the patient about adherence may confirm that this is the cause. However, if non-adherence is suspected but not volunteered, the options to confirm the notion are limited. Case reports have suggested using a $\mathrm{T}_{4}$ absorption test, which involves administering a bolus of $1 \mathrm{mg}$ oral $\mathrm{L}-\mathrm{T}_{4}$, as a strategy to identify pseudomalabsorption (12). Other reports have suggested using a bolus of weekly $\mathrm{T}_{4}$ as a way to identify and reduce non-adherence (13). One of the earliest studies to use weekly $\mathrm{T}_{4}$ showed that when compared with daily administration, the mean peak $\mathrm{fT}_{4}$ following weekly administration of $\mathrm{T}_{4}$ was significantly higher. However, none of the tissue markers of thyroid hormone effect changed significantly when compared with daily $\mathrm{T}_{4}$, and in addition, there was no evidence of treatment toxicity, including cardiac toxicity (14).

In our study, we identified patients where the biological causes mentioned earlier were excluded, and despite often high doses of $\mathrm{T}_{4}$, the patients remained hypothyroid. The patients were administered a weightrelated bolus dose of $\mathrm{L}_{-} \mathrm{T}_{4}$ and absorption measured over various time points. Patients then continued weekly administration of the $\mathrm{L}_{-} \mathrm{T}_{4}$ bolus for a 4 -week period and TSH levels were then measured. The main aims of this combination of tests were to first enable an assessment of $\mathrm{L}_{-} \mathrm{T}_{4}$ absorption then identify non-adherence by demonstration of a fall in TSH after the 4-week period. We also wished to assess the safety of once-weekly $\mathrm{T}_{4}$ administration.

\section{Materials and methods}

\section{Subjects}

Patient recruitment was from two sites within the United Kingdom: Sheffield Teaching Hospitals NHS Foundation Trust and Oxford University Hospitals NHS Trust Oxford. Patients were identified who despite the treatment with an adequate daily dose of $\mathrm{L}^{-\mathrm{T}_{4}}$ (daily dose $\geq 1.6 \mu \mathrm{g} / \mathrm{kg}$ per day) had failed to be rendered euthyroid (TSH persistently $>5.5 \mathrm{mU} / \mathrm{l}$ ). None of the selected patients were on drugs known to interfere with $\mathrm{L}-\mathrm{T}_{4}$ absorption/clearance and none were pregnant. All patients had a confirmed negative coeliac antibody screen and patients with known gastritis or malabsorptive pathology were excluded. No patient had a history of cardiac disease.

\section{$T_{4}$ absorption test/weekly $T_{4}$}

Patients were fasted from midnight before attending the Day Case Unit the following morning and remained fasting until the test was completed. A cannula was inserted and blood samples were taken for baseline $\mathrm{TSH} /$ free $\mathrm{T}_{4}\left(\mathrm{fT}_{4}\right)$ measurement. A week's supply of a weight-related bolus dose of $\mathrm{L}^{-\mathrm{T}_{4}}$ (mean $\mathrm{L}-\mathrm{T}_{4}$ dose administered $1.69 \pm 0.2 \mu \mathrm{g} / \mathrm{kg}$ per day) was administered orally under supervision and the patient remained supervised for a further $1 \mathrm{~h}$. Blood was collected via the cannula at 60-min intervals up to $240 \mathrm{~min}$ after ingestion for $\mathrm{fT}_{4}$ measurement (flushing between sampling with heparin was avoided). The patient continued on the same weekly dose of $\mathrm{L}_{-} \mathrm{T}_{4}$ for a total of 4 weeks. In one centre, the patients attended the Day Case Unit on a weekly basis to have the $\mathrm{L}_{-} \mathrm{T}_{4}$ administered under supervision where it was crushed and mixed with jam and at the other centre where $\mathrm{L}_{-} \mathrm{T}_{4}$ was not crushed. TSH was rechecked 1 week after the final dose.

\section{Hormone assays}

$\mathrm{FT}_{4}$ (normal range 10.5-20 pmol/l) and TSH (normal range $0.35-5.5 \mathrm{mU} / \mathrm{l}$ ) were measured using chemiluminescence immunoassay on a Siemens ADVIA Centaur analyser (Frimley, UK). Method reproducibility, expressed as the between-batch \% coefficient of variation, was as follows: $\mathrm{fT}_{4}, 5.1 \%$ at $11.0 \mathrm{pmol} / \mathrm{l}$, $4.5 \%$ at $27.8 \mathrm{pmol} / \mathrm{l}$ and $5.6 \%$ at $69.4 \mathrm{pmol} / \mathrm{l}$; $\mathrm{TSH}$, $4.8 \%$ at $0.47 \mathrm{mU} / \mathrm{l}, 4.7 \%$ at $6.8 \mathrm{mU} / \mathrm{l}$ and $4.3 \%$ at $38.5 \mathrm{mU} / \mathrm{l}$.

\section{Results}

Twenty-three patients were offered the above regimen (Sheffield, $n=18$; Oxford, $n=5$ ). The median age was 45 (range 20-88) years and median body weight was 87 (range 53.5-143) kg. The duration of hypothyroidism was a median of 8.5 (range 3-24) years and the cause was autoimmune disease $(n=17)$, total thyroidectomy $(n=3)$ and post-radioiodine $(n=3)$. The mean TSH before starting the study was $41.23 \pm 44.8 \mathrm{mU} / \mathrm{l}$

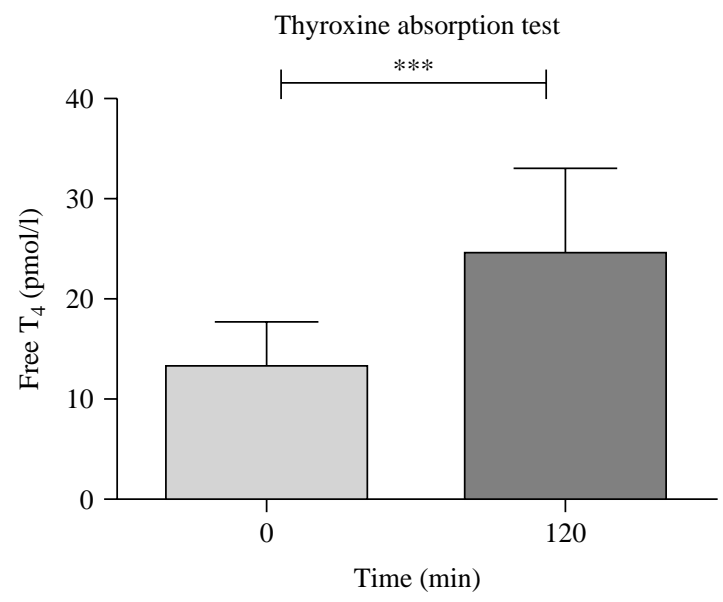

Figure 1 Thyroxine $\left(\mathrm{T}_{4}\right)$ absorption test demonstrating the significant rise in free $\mathrm{T}_{4}$ after a weight-related bolus of $\mathrm{T}_{4}(n=23$; mean + S.D.; $\left.{ }^{\star \star *} P<0.0001\right)$. 


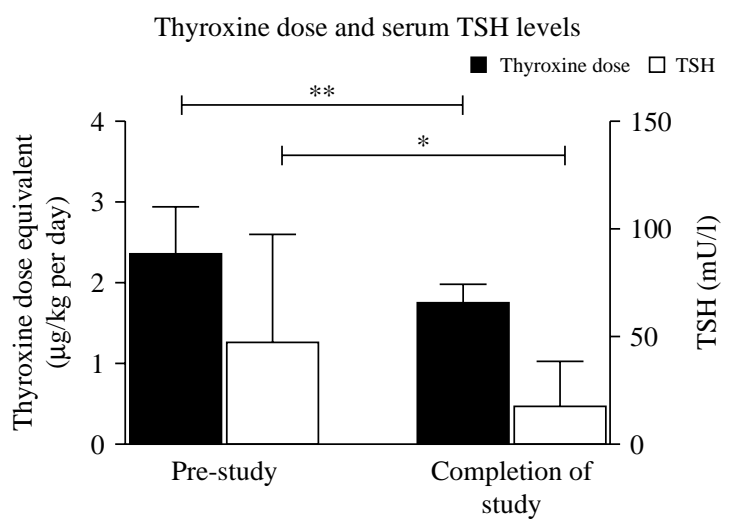

Figure 2 Levothyroxine ( $L-\mathrm{T}_{4}$ ) dose and TSH value pre- and post-study showing a significant reduction in TSH (white boxes; mean+s.D.: $\left.{ }^{*} P<0.05\right)$ despite a significant reduction in the $\mathrm{L}-\mathrm{T}_{4}$ dose (black boxes; mean +S.D.: ${ }^{\star \star} P<0.005$ ) for patients in whom their TSH improved $(n=17)$.

and mean pre-study $\mathrm{L}-\mathrm{T}_{4}$ dose was $2.31 \pm 0.56 \mu \mathrm{g} / \mathrm{kg}$ per day.

To identify the time for maximal absorption, the serum $\mathrm{fT}_{4}$ concentration following the oral weightrelated $\mathrm{L}_{-} \mathrm{T}_{4}$ bolus was measured at $60,120,180$ and $240 \mathrm{~min}$. In $82 \%$ of cases, the maximal rise in serum $\mathrm{fT}_{4}$ concentration occurred by $120 \mathrm{~min}$. At this time point, all patients $(n=23)$ showed a significant rise in $\mathrm{fT}_{4}$. The mean absolute increase in $\mathrm{fT}_{4}$ at $120 \mathrm{~min}$ was $54 \pm 3 \%$, from baseline $(13.1 \pm 4.5$ to $24.7 \pm 8.4 \mathrm{pmol} / \mathrm{l}$; $P<0.0001$ ) (IQ range 43-61\%) (Fig. 1). No differences were found between patients with spontaneous and iatrogenic hypothyroidism. Three of the patients with the most severe hypothyroidism (TSH $>150 \mathrm{mU} / \mathrm{l}$ ) showed the lowest actual rise in $\mathrm{fT}_{4}$ at $120 \mathrm{~min}$.

A final blood test was taken 4 weeks after starting treatment; TSH had reduced in $17 / 23(\sim 75 \%)$ cases. In these 17 cases, the mean TSH had reduced from $47.1 \pm 50.2$ to $17.6 \pm 20.6 \mathrm{mU} / \mathrm{l}$ (Fig. 2 : white bar). The reduction observed in TSH occurred despite using a weight-related dose of $\mathrm{L}-\mathrm{T}_{4}$, which was significantly less, compared with the daily equivalent, which was allegedly taken by the patients before the test $(P=0.005)$ (Fig. 2: black bar).
In six cases $(\sim 25 \%)$, despite a substantial rise in $\mathrm{fT}_{4}$ at $120 \mathrm{~min}$, indicating that $\mathrm{L}_{-} \mathrm{T}_{4}$ was being absorbed (mean $\mathrm{fT}_{4}$ : time $0 \mathrm{~min} 16.2 \pm 1$ vs time $120 \mathrm{~min} 27.5 \pm$ $3.2 \mathrm{pmol} / \mathrm{l}$ ), TSH remained elevated after 4 weeks of treatment (see Table 1). None of the patients experienced side effects as a result of the $\mathrm{T}_{4}$ absorption test or weekly L- $\mathrm{T}_{4}$ administration.

\section{Discussion}

Poor adherence with medication is a common problem in many chronic diseases (8). For patients who remain hypothyroid despite what would appear an appropriate amount of $\mathrm{L}_{-} \mathrm{T}_{4}$, the exclusion of any interfering drugs and other previously mentioned pathological causes need to be considered. In the majority of cases, the combination of a thorough history and examination should identify any contributing disease pathology. Rather than continuing to more detailed investigations, the issue of adherence needs to be addressed. However, if this is denied by the patient, this can often be difficult to demonstrate/confirm. Here, we describe a combination of a $\mathrm{T}_{4}$ absorption test, aiming to determine adequate absorption, followed by weekly $\mathrm{L}-\mathrm{T}_{4}$ bolus administration, which identified adherence issues in $75 \%$ of cases. Previous studies using a $\mathrm{T}_{4}$ absorption test have used a variable bolus dose between 1 and $2 \mathrm{mg}$, but this was not calculated on a weight-related basis $(12,15,16)$. In this study, a weight-related dose was used in each case. There is little data available to estimate what the 'normal' absorption following a weight-related weekly bolus of $\mathrm{L}^{-} \mathrm{T}_{4}$ would be. Here, we show in our series that a $\mathrm{fT}_{4}$ concentration taken 120 min post-ingestion can be used to represent maximal absorption. The mean elevation in $\mathrm{fT}_{4}$ at 120 min was $\sim 54 \%$. There was, however, no correlation between the incremental rise in $\mathrm{fT}_{4}$ demonstrated at $120 \mathrm{~min}$ and the degree of TSH suppression at 1 month. Severe hypothyroidism may impair absorption, presumably due to oedema of the small bowel mucosa, and it is likely for this reason that the patients with severe hypothyroidism (TSH $>150 \mathrm{mU} / \mathrm{l}$ ) had the lowest actual rise in $\mathrm{fT}_{4}$ at $120 \mathrm{~min}$. This is therefore a limitation of the test.

Table 1 Data for the six patients in whom their TSH remained elevated following the administration of a weight-related weekly levothyroxine dose. Note that the study dose used for the absorption test/weekly administration, in most cases, was significantly less than that taken before the study. The absorption test, however, showed both a similar incremental rise and peak at 120 min to the patients in whom their TSH was suppressed.

\begin{tabular}{|c|c|c|c|c|c|c|}
\hline $\begin{array}{l}\text { Patient } \\
\text { number }\end{array}$ & $\begin{array}{c}\mathrm{fT}_{\mathbf{4}} \text { baseline } \\
(\mathrm{pmol} / \mathrm{l})\end{array}$ & $\begin{array}{c}\mathbf{f T}_{\mathbf{4}} \\
120 \mathrm{~min}(\mathrm{pmol} / \mathrm{l})\end{array}$ & $\begin{array}{c}\text { TSH baseline } \\
(\mathrm{mU} / \mathrm{l})\end{array}$ & $\begin{array}{c}\text { TSH } 4 \text { weeks } \\
(\mathrm{mU} / \mathrm{l})\end{array}$ & $\begin{array}{c}\mathbf{T}_{4} \text { dose for absorption/ } \\
\text { weekly test (equivalent } \\
\mu \mathrm{g} / \mathrm{kg} \text { per day) }\end{array}$ & $\begin{array}{c}\mathbf{T}_{4} \text { dose pre-test } \\
\text { ( } \mu \mathrm{g} / \mathrm{kg} \text { per day) }\end{array}$ \\
\hline 7 & 15.3 & 22.6 & 12 & 21 & 1.6 & 2.6 \\
\hline 8 & 16.5 & 30.8 & 17 & 23 & 1.6 & 1.87 \\
\hline 9 & 14.8 & 30.4 & 33 & 53 & 1.6 & 2.85 \\
\hline 11 & 16.5 & 26.9 & 19.9 & 24.6 & 1.6 & 1.95 \\
\hline 18 & 17.8 & 29.7 & 55 & 72 & 1.6 & 2.54 \\
\hline 20 & 16.2 & 25 & 10.2 & 37.5 & 1.7 & 1.7 \\
\hline
\end{tabular}


None of the patients experienced side effects as a result of taking the whole week's dose of $\mathrm{L}_{-} \mathrm{T}_{4}$ at once. For six patients, a rise in TSH was observed. For the majority of these patients, the dose of $\mathrm{L}_{-} \mathrm{T}_{4}$ used was substantially less than that taken before entering the study. However, using the study dose, the absorption test showed a similar rise and peak at $120 \mathrm{~min}$ to the patients in whom their TSH was suppressed. The reasons for failure to normalise TSH concentrations in these six patients are unclear, but it may simply be that they have higher $\mathrm{L}_{-} \mathrm{T}_{4}$ requirements due to differences in metabolism or clearance. The administration of $\mathrm{L}-\mathrm{T}_{4}$ bolus for both the absorption test and the ongoing weekly $\mathrm{L}-\mathrm{T}_{4}$ was supervised in both centres, one centre where $\mathrm{T}_{4}$ was crushed and mixed with jam and the other centre where patients were observed swallowing the tablets whole. Interestingly, all the six patients who failed to improve with the weekly $\mathrm{L}-\mathrm{T}_{4}$ administration were from the group in which patients were given their tablets whole. It is plausible but highly unlikely (as the patients were supervised for $1 \mathrm{~h}$ after ingestion of $\mathrm{L}-\mathrm{T}_{4}$ ) that some of the patients may not have swallowed the tablets and that the poor adherence may have continued to be an issue. In addition, crushing of $\mathrm{L}-\mathrm{T}_{4}$ tablets has been shown to cause no reduction in the drug availability and in some cases it may actually enhance absorption (17). It is possible that crushing of tablets may have increased drug availability in patients whose TSH concentrations normalised and may have had a similar effect, if done, in the six patients whose TSH concentrations remained elevated. Unfortunately, it was not possible to confirm this hypothesis as these patients declined further repeat testing using crushed $\mathrm{L}-\mathrm{T}_{4}$ tablets. We did not specifically ask about grapefruit juice (18) or ingestion of soy protein supplements (19), both of which have been shown to affect absorption. It is, however, unlikely that this could have explained the lack of TSH suppression observed as massive quantities would have been needed to produce the elevation in TSH levels in those patients who did not respond. We would, however, recommend that these questions are included in an initial assessment.

After poor adherence is identified, different strategies can be adopted to improve treatment outcomes for the future. These should primarily be based on a closer understanding of the patients' perspectives of their illness, lifestyle and health beliefs, rather than the perceptions and expectations of health care professionals (8). One of the most commonly advocated ways to improve compliance is the improvement of the doctor-patient relationship (20).

\section{Conclusion}

The $\mathrm{T}_{4}$ absorption test helps to demonstrate that $\mathrm{T}_{4}$ can be absorbed into the systemic circulation and the current study shows that the mean absolute incremental rise in $\mathrm{fT}_{4}$ at $120 \mathrm{~min}$ is $\sim 54 \%$ (time $0 \mathrm{~min} 13.1 \pm 4.5$ time vs $120 \mathrm{~min} 24.7 \pm 8.4 \mathrm{pmol} / \mathrm{l})$ in patients not known to have malabsorptive pathology.

Weekly L- $\mathrm{T}_{4}$ administration showed that the majority of patients $(75 \%)$ who were administered a weekly equivalent dose, which was lower than the equivalent dose previously taken on a daily basis, showed a significant improvement in their TSH at 4 weeks, demonstrating that adherence was indeed an issue.

We recommend that the measurement of serum $\mathrm{fT}_{4}$ concentration $120 \mathrm{~min}$ after the ingestion of a weightrelated dose of crushed $\mathrm{L}^{-} \mathrm{T}_{4}$ can be used to show maximal $\mathrm{T}_{4}$ absorption; weekly administration of the same dose of $\mathrm{L}_{-} \mathrm{T}_{4}$ and measurement of serum $\mathrm{fT}_{4}$ and TSH concentration thereafter should be used to demonstrate non-adherence with treatment.

\section{Declaration of interest}

The authors declare that there is no conflict of interest that could be perceived as prejudicing the impartiality of the research reported.

\section{Funding}

This research did not receive any specific grant from any funding agency in the public, commercial or not-for-profit sector.

\section{Author contribution statement}

$\mathrm{J} \mathrm{N}$ Walker collected and analysed the data and contributed to the writing of the manuscript. P Shillo, V Ibbotson and A Vincent collected the data; N Karavitaki, A P Weetman, J A H Wass and A Allahabadia contributed to the writing of the original manuscript and reviewed the final manuscript.

\section{References}

1 Harington CR \& Barger G. Chemistry of thyroxine: constitution and synthesis of thyroxine. Biochemical Journal 192721 169-183.

2 Boelaert K \& Franklyn JA. Thyroid hormone in health and disease. Journal of Endocrinology 2005187 1-15. (doi:10.1677/joe.1. 06131)

3 Mandel SJ, Brent GA \& Larsen PR. Levothyroxine therapy in patients with thyroid disease. Annals of Internal Medicine 1993119 492-502.

4 Read DG, Hays MT \& Hershman JM. Absorption of oral thyroxine in hypothyroid and normal man. Journal of Clinical Endocrinology and Metabolism 1970 30 798-799. (doi:10.1210/jcem-30-6-798)

5 Liwanpo L \& Hershman JM. Conditions and drugs interfering with thyroxine absorption. Best Practice \& Research. Clinical Endocrinology E Metabolism 200923 781-792. (doi:10.1016/j.beem. 2009.06.006)

6 Benvenga S, Bartolone L, Pappalardo MA, Russo A, Lapa D, Giorgianni G, Saraceno G \& Trimarchi F. Altered intestinal absorption of L-thyroxine caused by coffee. Thyroid $2008 \mathbf{1 8}$ 293-301. (doi:10.1089/thy.2007.0222)

7 Tonjes A, Karger S, Koch CA, Paschke R, Tannapfel A, Stumvoll M \& Fuhrer D. Impaired enteral levothyroxine absorption in hypothyroidism refractory to oral therapy after thyroid ablation for papillary thyroid cancer: case report and kinetic studies. Thyroid 200616 1047-1051. (doi:10.1089/thy.2006.16.1047) 
8 Vermeire E, Hearnshaw H \& Van Royen P. Patient adherence to treatment: three decades of research. A comprehensive review. Journal of Clinical Pharmacy and Therapeutics 200126 331-342. (doi:10.1046/j.1365-2710.2001.00363.x)

9 Elliott RA, Shinogle JA, Peele P, Bhosle M \& Hughes DA. Understanding medication compliance and persistence from an economics perspective. Value in Health 200811 600-610. (doi:10.1111/j.1524-4733.2007.00304.x)

10 Melnikow J \& Kiefe C. Patient compliance and medical research: issues in methodology. Journal of General Internal Medicine 19949 96-105. (doi:10.1007/BF02600211)

11 Morris LS \& Schulz RM. Medication compliance: the patient's perspective. Clinical Therapeutics 199315 593-606.

12 Lips DJ, van Reisen MT, Voigt V \& Venekamp W. Diagnosis and treatment of levothyroxine pseudomalabsorption. Netherlands Journal of Medicine 200462 114-118.

13 Rangan S, Tahrani AA, Macleod AF \& Moulik PK. Once weekly thyroxine treatment as a strategy to treat non-compliance. Postgraduate Medical Journal 200783 e3. (doi:10.1136/pgmj. 2007.060244)

14 Grebe SK, Cooke RR, Ford HC, Fagerstrom JN, Cordwell DP, Lever NA, Purdie GL \& Feek CM. Treatment of hypothyroidism with once weekly thyroxine. Journal of Clinical Endocrinology and Metabolism 199782 870-875. (doi:10.1210/jc.82.3.870)
15 Ain K, Refetoff S, Fein H \& Weintraub B. Pseudomalabsorption of levothyroxine. Journal of the American Medical Association 1991 266 2118-2120. (doi:10.1001/jama.1991.03470150090036)

16 Payer J, Sladekova K \& Kinova S. Autoimmune thyroiditis with severe hypothyroidism resistant to the treatment with high peroral doses of thyroxine: case report. Endocrine Regulations 2000 34 189-193.

17 Yamamoto T. Tablet formulation of levothyroxine is absorbed less well than powdered levothyroxine. Thyroid 200313 1177-1181. (doi:10.1089/10507250360731596)

18 Lilja JJ, Laitinen K \& Neuvonen PJ. Effects of grapefruit juice on the absorption of levothyroxine. British Journal of Clinical Pharmacology 200560 337-341. (doi:10.1111/j.1365-2125.2005.02433.x)

19 Bell DS \& Ovalle F. Use of soy protein supplement and resultant need for increased dose of levothyroxine. Endocrine Practice 20017 193-194. (doi:10.4158/EP.7.3.193)

20 Deber RB. Physicians in health care management: 7. The patient-physician partnership: changing roles and the desire for information. CMAJ: Canadian Medical Association Journal 1994151 $171-176$.

Received 26 November 2012

Revised version received 25 February 2013

Accepted 3 April 2013 